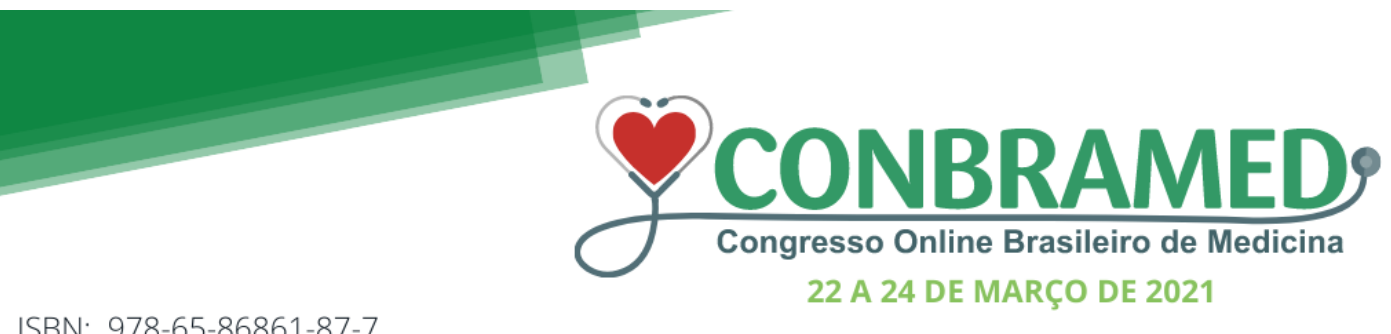

ISBN: $978-65-86861-87-7$

22 A 24 DE MARÇO DE 2021

\title{
RELAÇÃO ENTRE DOENÇA DE KAWASAKI E SÍNDROME INFLAMATÓRIA MULTISSISTÊMICA EM CRIANÇAS ASSOCIADA À COVID-19: EVOLUÇÃO E CONDUTA
}

Congresso Online Brasileiro de Medicina, 1ạ edição, de 06/12/2021 a 08/12/2021

ISBN dos Anais: 978-65-86861-87-7.

DIAS; Amanda Gaio ${ }^{1}$, VERONA; Jaqueline Guinallia 2, SILVA; Larissa Ramos de Lima e ${ }^{3}$, PEREIRA; Letícia Marsari ${ }^{4}$, SANTOS; Samira Coladão dos 5

\section{RESUMO}

No mundo todo foi observada uma aceleração da incidência de COVID-19, que brevemente evoluiu para uma emergência na saúde global. Em crianças, a infecção pelo novo coronavírus da Síndrome Respiratória Aguda Grave (SARS-CoV-2) geralmente se apresenta de forma assintomática ou sintomática branda, sendo 1 a $5 \%$ os casos sintomáticos. No entanto, uma minoria evolui para sintomáticos graves desenvolvendo - que a Organização Mundial de Saúde (OMS) chamou de Síndrome Inflamatória Multissistêmica em crianças (MIS-C), a qual possui características semelhantes à Doença de Kawasaki (DK), uma doença rara e grave com potencial de morbidade persistente, tanto em aspecto fisiológico imunomediado quanto em sinais clínicos, podendo levar a cardiopatias graves, exigindo desse modo cuidados intensivos. Nessa perspectiva, o objetivo do presente estudo foi realizar uma revisão de literatura que demonstra a relação entre a DK e a Síndrome Inflamatória Multissistêmica desencadeada por COVID-19 em crianças, explicitando sua gravidade e a necessidade de intervenção adequada, e a partir disso compreender sua dimensão no contexto atual da pandemia de SARS-CoV2. Com o intuito de ampliar a compreensão das possíveis explicações e implicações de tal relação, foi realizada uma busca nas bases de dados Scientific Electronic Library Online (SciELO), PubMed, Biblioteca Virtual em Saúde (BVS) e UpToDate, incluindo artigos nos idiomas português e inglês entre os anos de 2020 e 2021. A desregulação imunológica que ocorre na MIS-C e na DK mostra semelhança quanto à evolução clínica, afetando muitos órgãos e sistemas e sendo potencialmente grave, constituindo portanto a MIS-C como uma possível DK rara e complicada. Há constantes avanços dos métodos diagnósticos e de tratamentos, com preconização de terapias medicamentosas como a administração de imunoglobulina intravenosa (IgIV), a qual diminuiu drasticamente a frequência do desenvolvimento de aneurismas e a mortalidade. As complicações a longo prazo ainda não são totalmente conhecidas, mas há evidências de distúrbios no sistema cardiovascular, renal e pulmonar, com claro risco de óbito caso o quadro não seja rapidamente reconhecido. Significativas pesquisas acerca do tema têm sido desenvolvidas para a faixa etária pediátrica, sendo crescente a elucidação da relação entre a Síndrome Inflamatória Multissistêmica e a DK. Contudo é reforçada a importância do diagnóstico precoce da MIS-C e a implicação de intervenções terapêuticas de alto poder resolutivo, em busca do tratamento definitivo e a fim de evitar as complicações e consequente mortalidade associada à gravidade 
da doença.

PALAVRAS-CHAVE: Coronavírus, Criança, Inflamação, Síndrome de linfonodos mucocutâneos 